\title{
As tecnologias digitais na aprendizagem das crianças e no envolvimento parental no Jardim de Infância: Estudo exploratório das necessidades das educadoras de infância
}

\author{
Dionísia Laranjeiro', Maria João Antunesii \& Paula Santosiii \\ Universidade de Aveiro, Portugal
}

Resumo

É cada vez mais comum o uso das tecnologias digitais por pais e educadores de infância para realizar atividades promotoras de aprendizagem com as crianças, tais como fazer uma pesquisa na Internet ou jogar um jogo didático. A conceção de uma plataforma tecnológica que promova a comunicação entre pais e educadores poderá potenciar o envolvimento parental na aprendizagem das crianças e criar novas dinâmicas no jardim de infância. Com este estudo, baseado em entrevistas a quatro educadoras, pretende-se averiguar como é utilizada a tecnologia no jardim de infância para realizar atividades com as crianças e para comunicar com os pais, de forma a facilitar o seu envolvimento. Também se pretende perceber como estas atividades podem ser ampliadas, usando uma plataforma digital com funcionalidades específicas. Os resultados indicam que a plataforma deve reunir informações oficiais do jardim de infância e das atividades realizadas com as crianças, contactos diretos dos pais, sugestões e links para recursos educacionais.

Palavras-chave Jardim de infância; TIC; Envolvimento parental; aprendizagem 


\section{Introdução}

Este artigo insere-se numa investigação em curso, mais alargada ${ }^{1}$, em que se pretende desenvolver uma plataforma tecnológica para o envolvimento parental na aprendizagem das crianças que frequentam o jardim de infância (JI), integrando pais e educadores de infância em todo o processo, desde o levantamento de necessidades para definição das especificações funcionais, aos testes e melhorias do protótipo tecnológico, utilização da plataforma durante um ano letivo, terminando com um estudo sobre o impacto da plataforma no envolvimento parental na aprendizagem das crianças que frequentam o Jl. Nesta investigação participam quatro salas de três $\mathrm{Jl}$ da região de Aveiro: duas salas em duas instituições privadas de solidariedade social (Jl1 e Jl2) e duas salas numa instituição privada (Jl3), envolvendo quatro educadoras de infância e os encarregados de educação dos respetivos grupos de crianças. Numa primeira fase da investigação, foi já realizado um inquérito por questionário aos encarregados de educação para auscultar as suas necessidades e expectativas relativamente à plataforma. Os resultados mostram que os encarregados de educação valorizam algumas funcionalidades: notícias e calendário de eventos, galeria de fotografias e vídeos de projetos das crianças e mensagens privadas com o educador. A maior vantagem da plataforma é aceder a informações atualizadas sobre o trabalho realizado no jardim de infância. Uma preocupação geral dos encarregados de educação é a proteção de informações pessoais, em particular a partilha de fotografias onde as crianças são identificadas (Laranjeiro, Antunes, \& Santos, 2016). Nesta fase pretende-se auscultar as educadoras, para incluir as suas perspetivas e necessidades numa plataforma que deve melhorar a comunicação com os encarregados de educação e promover o envolvimento parental na aprendizagem das crianças.

\section{Enquadramento}

Uso da tecnologia para atividades de aprendizagem com as crianças no jardim de infância (JI)

Atualmente assistimos à proliferação do uso da tecnologia no dia a dia das famílias, para fins diversos, desde o trabalho ao entretenimento, comunicação e organização pessoal. As crianças crescem familiarizadas com 
tecnologias como os computadores, a Internet, os videojogos, os tablets e os telemóveis, usando-as para brincar, aprender e comunicar. A linguagem digital faz parte das vidas destes nativos digitais, podendo até alterar os seus padrões de pensamento e a forma como aprendem (Prensky, 2001). A aprendizagem das crianças mais novas é intuitiva e orientada à ação. A tecnologia, em particular o computador, pode ser usada para construção do conhecimento, pois oferece inúmeras possibilidades de aprendizagem sobre o mundo envolvente (Papert, 1996). Amante (2007) refere vários estudos que realçam os contributos das Tecnologias da Informação e Comunicação (TIC) na aprendizagem das crianças pequenas, nomeadamente ao nível do desenvolvimento da linguagem (fluência e complexidade de discurso, comunicação verbal e colaboração, linguagem escrita, vocabulário, sintaxe e reconhecimento de palavras, entre outros); pensamento matemático (contagem, classificação, pensamento lógico, geométrico e espacial, resolução de problemas); conhecimento do mundo e contacto com outras realidades naturais, sociais e culturais; educação para a diversidade, multiculturalidade e formação cívica. A importância do tema é reforçada com recomendações para a introdução das TIC na educação (United Nations Educational, Scientific and Cultural Organization [UNESCO], 2011), o Policy Brief da UNESCO para uso das TIC na educação pré-escolar (Kalas, 2012), ou a declaração de posição da National Association for the Education of Young Children (NAEYC, 2012), que defende a integração de tecnologia e media interativos como ferramentas de aprendizagem na educação pré-escolar. As ferramentas tecnológicas devem satisfazer objetivos específicos de aprendizagem, tais como envolver o aluno na construção do conhecimento, potenciar a criatividade e a expressividade, promover a interação e o trabalho colaborativo, explorar formas de aprendizagem autónoma e permitir a apresentação dos seus trabalhos a um público (Crook, 2008).

Naturalmente, e cada vez mais, os $\mathrm{Jl}$ introduzem dispositivos tecnológicos nas suas atividades com as crianças. Neste domínio, é necessário que o educador de infância tenha a confiança necessária para planear atividades de aprendizagem com recurso às tecnologias (Costa, Rodriguez, \& Fradão, 2012). O educador terá como funções proporcionar atividades com materiais adaptados aos interesses das crianças, como jogos digitais; monitorizar o uso e o tempo ao computador; dar suporte técnico; 
apoiar, intervindo em algumas tarefas, e, gradualmente, ir deixando a criança ser mais autónoma no uso do computador. Poderá ainda preparar questões, incentivar o pensamento crítico, a reflexão e a experimentação, e observar a criança, para compreender o seu processo de aprendizagem e o desenvolvimento do seu pensamento, aquando da utilização da tecnologia (Clements \& Sarama, 2002). Brito (2010) efetuou um questionário a educadores de infância de todo o país, para verificar atitudes e práticas na utilização do computador no Jl. Das 363 respostas que obteve, pôde concluir que a maioria dos educadores considera a utilização das TIC muito importante para a aprendizagem das crianças, em particular nas áreas de conteúdo, como a Matemática e a Língua Portuguesa. Grande parte dos educadores refere alterações positivas nas crianças, a nível cognitivo e motor, associadas ao manuseamento do computador.

\section{Uso da tecnologia para envolvimento parental}

O envolvimento parental é um tema muito abrangente, que implica a participação dos pais em atividades relacionadas com os contextos educativos formais frequentados pelos seus filhos (Laranjeiro, Antunes, \& Santos, 2016). Na educação pré-escolar, o envolvimento parental compreende a participação em atividades na sala do JI (por ex., ler um livro, fazer um bolo), ações de voluntariado (por ex., organizar um evento), ou mesmo participação na definição do plano pedagógico. O envolvimento parental na aprendizagem pressupõe ainda, por um lado, saber o que a criança aprende no Jl, dialogando com ela e comunicando com o educador para conhecer o seu progresso; por outro lado, ajudar a criança a progredir, realizando atividades educativas em casa (Reynolds \& Shlafer, 2010). A importância do envolvimento parental tem sido objeto de várias investigações, das quais se destacam, seguidamente, algumas conclusões. $\mathrm{O}$ envolvimento parental tem um efeito significativo na adaptação da criança e no sucesso na aprendizagem, independentemente de outros fatores, como a classe social (Desforges \& Abouchaar, 2003). O envolvimento em casa tem um papel vital nos resultados dos alunos e na atitude positiva face à escola (Melhuish et al., 2008). As expetativas que os pais transmitem aos filhos sobre o que aspiram para eles a nível académico têm forte influência no seu sucesso (Fan \& Chen, 2001). Nas crianças em idade

pré-escolar, acresce o impacto do envolvimento parental no desenvolvimento geral, no desenvolvimento cognitivo e na preparação para a escola (Hilado, 
Kallemeyn, \& Phillips, 2013). Há uma relação entre o envolvimento parental no Jl e o desempenho das crianças na leitura e na matemática (Sonnenschein, Stapleton, \& Metzger, 2014). As relações positivas entre educadores e pais influenciam a aquisição de competências sociais das crianças (Diamond, Justice, Siegler, \& Snyder, 2013). Uma comunicação escola-família eficaz está também associada ao sucesso académico (Lunts, 2003). Quando os pais comunicam construtivamente com os professores e participam em atividades escolares, têm uma maior compreensão do que as suas crianças devem aprender e como podem melhorar a sua educação, em casa (Stevenson \& Baker, 1987). O feedback e as recomendações dos educadores podem ajudar as famílias a criar experiências de aprendizagem em casa, baseadas no que as crianças aprendem no Jl (Fantuzzo et al., 2013). A comunicação entre a escola e a família está na base do envolvimento parental. Como o estilo de vida das pessoas tem vindo a mudar, as formas de comunicação também evoluem. As ferramentas tecnológicas, como websites, sites de redes sociais, blogs ou e-mails, originam novos canais de comunicação de que os educadores podem tirar partido para envolver os pais, partilhar experiências e melhorar a relação escola-família.

Alguns projetos de investigação em que se promoveu o envolvimento parental no Jl, através de ferramentas tecnológicas, apresentam resultados positivos a considerar:

- No Jl do Campus da Universidade de Michigan-Dearborn, EUA, que recebe 140 crianças entre 1 e 6 anos, a tecnologia é usada como forma de documentação das atividades de aprendizagem, permitindo a organização de ideias, pensamento crítico, reflexão e apresentação a uma comunidade. Neste contexto, promoveu-se o uso de uma rede social privada para partilha entre educadores e pais, o que manteve os pais atualizados sobre as atividades dos filhos e envolveu os pais em atividades conjuntas com os filhos e com os educadores. Os educadores confirmaram que quanto mais publicavam, mais os pais participavam. A tecnologia instituiu-se como uma forma de comunicação e colaboração privilegiada entre os membros da comunidade de aprendizagem da criança (Hong \& Trepanier-Street, 2004).

- No Centro de Educação Infantil Maria Bittencourt Saut, no Brasil, o uso de uma plataforma digital para partilhar com os pais os 
trabalhos desenvolvidos no $\mathrm{Jl}$ promoveu a participação e o envolvimento a partir de casa. Os pais comentavam, reagiam e acompanhavam o processo educacional dos filhos, de forma mais intensa. As relações virtuais permitiram uma melhoria significativa no processo educacional da instituição (Santos, 2013).

- Num projeto de investigação desenvolvido no Jl de Rio Covo Barcelos, o uso de uma rede social personalizada para comunicação e partilha de trabalhos com os pais facilitou e promoveu a aproximação dos pais à instituição. Os pais participaram ativamente, contribuindo com o seu conhecimento para o desenvolvimento de projetos. Tiveram a oportunidade de conhecer o trabalho desenvolvido em contexto de sala e prolongar a aprendizagem em casa, comentando, partilhando e sugerindo conteúdos (Faria \& Ramos, 2011).

- Num Jl do Agrupamento Amadeo de Souza-Cardoso - Amarante, implementou-se um projeto de utilização de recursos digitais para promover o desenvolvimento de multiliteracias, no qual as crianças usaram o computador para criar narrativas e partilhar posteriormente num blog. $\mathrm{O}$ acesso ao blog permitiu aos pais participarem e envolverem-se, comentando os projetos das crianças, com afinco. Estes comentários alargaram afetos e relações das crianças, contribuindo para o seu desenvolvimento e para uma aprendizagem construtiva e colaborativa (Teixeira, 2014).

- Um estudo de caso num Jl de Felgueiras, onde as crianças produziram vídeos e publicaram na plataforma de vídeos YouTube, veio mostrar que esta tecnologia facilitou o desenvolvimento cognitivo e social, a conversação, colaboração e familiarização com ferramentas de edição de imagem e áudio. A possibilidade de os pais verem, em casa, os vídeos partilhados, o número de visualizações e os comentários deixados aos vídeos suscitou entusiasmo, valorizando e incentivando à continuação do trabalho (Braga, Ramos, \& Braga, 2015).

- O uso de um blog para averiguar o seu impacto no processo de aprendizagem digital e intergeracional, que decorreu no $\mathrm{Jl}$ de Rubiães - Paredes de Coura, envolvendo um grupo heterogéneo de 19 crianças e um grupo de utentes de um centro de convívio, 
mostrou favorecer o desenvolvimento das crianças e dos idosos. Ao mesmo tempo, a partilha online das atividades intergeracionais incitou o interesse positivo e a participação das famílias. O blog cumpriu uma função informativa e de aproximação da família ao Jl, servindo também como ferramenta de e-learning para as crianças (Pereira, 2014).

Destes projetos sintetizam-se alguns benefícios resultantes do envolvimento parental com ferramentas tecnológicas: maior participação e feedback dos pais; maior conhecimento do trabalho desenvolvido no jardim de infância; melhor relação entre pais e educadores; e aumento da capacidade dos pais para promover a aprendizagem das crianças em casa. Estes estudos reforçam a pertinência do desenvolvimento de uma plataforma digital de envolvimento parental na aprendizagem das crianças, dinamizada por educadores de infância e encarregados de educação. As educadoras de infância participantes no projeto serão as principais dinamizadoras da plataforma, pelo que foi primordial compreender o que poderia levar à sua adesão e utilização.

\section{Método}

\section{Objetivos do estudo}

Este artigo focaliza-se num estudo diagnóstico e exploratório com as educadoras, de forma a contemplar as suas necessidades nas especificações funcionais da plataforma. Assim, elaborou-se um inquérito por entrevista, com os seguintes objetivos específicos:

- Obter informação sobre as práticas das educadoras relativamente à utilização de ferramentas digitais para realizar atividades com as crianças no $\mathrm{Jl}$ e, também, para comunicar e envolver os encarregados de educação na sua aprendizagem;

- Averiguar qual a perceção das educadoras sobre o uso de uma plataforma digital específica para envolvimento parental e dinamização de atividades com as crianças: i) suas vantagens e desvantagens; ii) dispositivos a utilizar e frequência de utilização; iii) conteúdos, ferramentas e dinâmicas que a plataforma deverá contemplar. 


\section{Sujeitos participantes no estudo}

A entrevista foi realizada às quatro educadoras de infância dos $\mathrm{Jl}$ participantes nesta investigação: uma educadora (Ed1) do Jl1, com um grupo de 22 crianças e 20 encarregados de educação; uma educadora (Ed2) do Jl2, com um grupo de 24 crianças e 24 encarregados de educação; uma educadora ( $E d 3)$ do JI 3, com um grupo de 21 crianças e 20 encarregados de educação; uma educadora (Ed4) do Jl3, com um grupo de 23 crianças e 20 encarregados de educação.

\section{Planificação das entrevistas}

A entrevista semiestruturada foi o meio escolhido para inquirir as educadoras, uma vez que a intenção da recolha de dados era obter informação mais detalhada e aprofundada, de um pequeno grupo selecionado (Coutinho, 2013).

Para a planificação das entrevistas seguiu-se o modelo de Kvale (cit. por Cohen, Manion, \& Morrison, 2007), constituído por sete etapas: 1) definição da temática; 2) conceção do guião; 3) entrevista; 4) transcrição; 5) análise; 6) verificação; e 7) escrita de relatório. A etapa de verificação ocorre em paralelo com as restantes etapas da planificação e consiste em providenciar mecanismos que garantam a fiabilidade e validade dos dados, como por exemplo: a transcrição dos dados para meio escrito, espelhando os dados áudio gravados; uma análise rigorosa e fiel dos dados recolhidos; o relatório transmitindo os resultados de forma justa e rigorosa.

A primeira etapa - definição da temática - foi determinada, desde o início, como sendo a conceção de uma plataforma digital para o envolvimento parental na aprendizagem das crianças que frequentam o Jl, tendo em conta as necessidades identificadas pelos educadores de infância.

Foi concebido um guião para as entrevistas semiestruturadas (Quadro 1), com questões previamente formuladas, para orientação do entrevistador e para replicação em todas as entrevistas. Desta forma, garantiu-se que todas as educadoras respondessem a perguntas semelhantes, facilitando posteriormente a análise de conteúdo. Quando a entrevista é semiestruturada, o entrevistador tem alguma flexibilidade para aprofundar determinadas questões, dependendo do respondente e da sua experiência e 
conhecimento, o que poderá trazer contributos diferentes ao estudo (Bogdan \& Biklen, 1994). Além disso, o facto de o guião ser comum às quatro entrevistas permitiu comparar os dados gerados (Fraenkel \& Wallen, 2009).

As questões foram pensadas para dar resposta aos objetivos definidos para a entrevista. Optou-se por usar perguntas abertas, que permitissem explorar com mais profundidade o conhecimento do entrevistado. Quanto ao formato, optou-se por questões de experiência, para que o entrevistado descrevesse as suas atividades passadas e presentes; e questões de opinião, para indagar o que pensava acerca de determinados tópicos, podendo incluir as respetivas crenças, atitudes e objetivos (Cohen et al., 2007). Seguidamente, apresenta-se o guião da entrevista semiestruturada (Quadro 1).

\section{Quadro 1 - Guião das entrevistas realizadas às educadoras de infância}

\begin{tabular}{|c|c|c|}
\hline Momento/objetivo & Conteúdo/questão & Dur. \\
\hline $\begin{array}{l}\text { Introdução } \\
\text { - Clarificar o propósito } \\
\text { e o protocolo a seguir }\end{array}$ & $\begin{array}{l}\text { - Informar sobre a duração da entrevista; solicitar permissão } \\
\text { para a sua gravação áudio. }\end{array}$ & $1 \mathrm{~min}$. \\
\hline $\begin{array}{l}\text { Obter informação sobre } \\
\text { dinâmicas realizadas } \\
\text { com as crianças }\end{array}$ & $\begin{array}{l}\text { - Costuma usar meios digitais para fazer atividades com as } \\
\text { crianças no JI? } \\
\text { - Que meios utiliza para realizar atividades digitais com as } \\
\text { crianças? (Computador, tablet, webcam, scanner, impressora, } \\
\text { máquina fotográfica, ...) } \\
\text { - Que tipo de aplicações e conteúdos digitais usa com as } \\
\text { crianças nas suas atividades? } \\
\text { - Com que frequência realiza este tipo de atividades? } \\
\text { - Que outro tipo de aplicações e conteúdos digitais gostaria de } \\
\text { explorar com as crianças, que ainda não tenha explorado? }\end{array}$ & $5 \mathrm{~min}$. \\
\hline $\begin{array}{l}\text { Obter informação sobre } \\
\text { dinâmicas realizadas } \\
\text { com os pais }\end{array}$ & $\begin{array}{l}\text { - Costuma usar meios digitais para comunicar com os pais } \\
\text { sobre o que as crianças aprendem do JI? } \\
\text { - Se sim, quais? - Se não, porquê? } \\
\text { - Que tipo de dinâmicas poderiam ser dinamizadas com base } \\
\text { numa ferramenta destas, que envolvesse os educadores, os } \\
\text { pais e as crianças? } \\
\text { Dar sugestões (envio de recados, informação sobre trabalho } \\
\text { semanal, partilha de fotografias, desenhos, vídeos de } \\
\text { atividades em casa e Jl, comentários, sugestões dos } \\
\text { educadores para exploração em casa, ...). }\end{array}$ & $5 \mathrm{~min}$. \\
\hline $\begin{array}{l}\text { Obter informação sobre } \\
\text { modo de dinamização } \\
\text { da plataforma }\end{array}$ & $\begin{array}{l}\text { - Com que frequência acha que consultará e atualizará a } \\
\text { informação na plataforma (diária / semanal / mensal)? } \\
\text { - Com que dispositivos consultará ou enviará informação para } \\
\text { a plataforma (telemóvel, tablet, computador)? }\end{array}$ & $3 \mathrm{~min}$. \\
\hline $\begin{array}{l}\text { Obter informação sobre } \\
\text { pontos fortes e } \\
\text { constrangimentos para } \\
\text { a implementação }\end{array}$ & $\begin{array}{l}\text { - Quais são, para si, as vantagens da utilização de uma } \\
\text { plataforma digital para envolver os pais? } \\
\text { - Quais são as desvantagens da utilização de uma plataforma } \\
\text { digital para envolver os pais? }\end{array}$ & $5 \mathrm{~min}$. \\
\hline Conclusão & $\begin{array}{l}\text { Agradecer a disponibilidade para a realização da entrevista; } \\
\text { propor futuros contactos, caso surjam dúvidas relativas aos } \\
\text { assuntos conversados e para validação do resumo. }\end{array}$ & $1 \mathrm{~min}$. \\
\hline
\end{tabular}




\section{Realização das entrevistas}

O passo seguinte foi a realização das entrevistas. As entrevistadas foram contactadas com antecedência para marcar a data e combinar como seria conduzida a entrevista. Foram explicados o objetivo e o modo como os dados recolhidos seriam usados. Foi concedida autorização para citações verbais e gravação das entrevistas.

As entrevistas foram conduzidas presencialmente. Por coincidir com a época natalícia, de festas e avaliações, para as educadoras, ajustaram-se as datas conforme a sua disponibilidade, tendo sido todas realizadas no decorrer do mês de dezembro de 2015. Ao longo das entrevistas, além da gravação áudio, foram tomadas notas nos guiões impressos, para ajudar a formular novas perguntas ou alterar a ordem das perguntas planificadas. A duração das entrevistas variou entre oito e quinze minutos, aproximadamente.

\section{Metodologia de análise das entrevistas}

Após a realização das entrevistas, seguiu-se a etapa de transcrição, na qual os ficheiros de áudio foram convertidos em ficheiros de texto, para posterior análise de conteúdo. A análise de conteúdo tem por objetivo sistematizar e tratar, de forma metódica, o grande volume de dados qualitativos recolhidos. Para isso, numa primeira abordagem procedeu-se a uma leitura do corpus documental para percecionar possibilidades de análise e encontrar aspetos relacionados com os objetivos e questões de investigação (Bardin, 1977).

O texto transcrito foi segmentado em unidades de análise. A unidade de análise escolhida foi o excerto de frase, retirada dos dados gravados dos participantes, que pode ser associada a um tópico representado numa categoria de codificação (Bogdan \& Binklen, 1994).

A leitura dos documentos transcritos ajudou a desenvolver um modelo de classificação, ordenação e categorização das unidades de análise.

A análise foi feita com recurso ao software de análise qualitativa de dados NVivo. Este software permite: introduzir fontes, que podem ser diferentes tipos de media (texto, áudio, vídeo); editar, organizar e interligar documentos; criar categorias e codificar, pesquisar e cruzar dados para responder às perguntas de investigação. No NVivo criou-se a lista de 
categorias de codificação, composta por uma estrutura de nós em árvore, da seguinte forma:

- Dinâmicas com as crianças - a que se associam aspetos relacionados com o uso da tecnologia pelas crianças no Jl, divididas em subcategorias:

- Tecnologias usadas pelas crianças no Jl;

- Aplicações e conteúdos digitais usados no Jl;

- Atividades que as educadoras realizam com tecnologia;

o Frequência de realização de dinâmicas digitais;

o Constrangimentos às dinâmicas digitais;

- Dinâmicas com os pais - a que se associam aspetos relacionados com a comunicação pais-Jl, com base na tecnologia, sejam os atuais ou os potenciais. Divide-se nas subcategorias:

o Meios digitais usados na comunicação com pais;

o Dinâmicas possíveis com a futura plataforma;

- Uso da Plataforma - a que se associam questões práticas relacionadas com o uso da futura plataforma. Divide-se nas subcategorias:

o Frequência de uso;

o Dispositivo de uso;

- Vantagens e desvantagens - a que se associam todas as opiniões das educadoras relativamente aos pontos fortes e/ou fracos da futura plataforma. Subdivide-se em:

o Vantagens na utilização da plataforma;

- Constrangimentos à utilização da plataforma.

Cada subcategoria é ainda subdividida em novos nós, que serão mencionados ao longo da apresentação dos resultados. Após a codificação, o NVivo indica o número de unidades de análise associado a cada categoria, subcategoria e nós das subcategorias, dando uma visão geral da expressividade de cada tópico, mostrando quantas vezes foram codificadas as unidades de análise, em cada categoria, e por que fontes. 


\section{Resultados}

Para a apresentação dos resultados da análise de conteúdo das entrevistas às educadoras, foram criados quadros com alguns exemplos de unidades de registo relativamente a cada nó de cada subcategoria, dentro das categorias de codificação (Quadros 2 a 5). Os quadros apresentam ainda o número de fontes (educadoras) que mencionou cada nó. A primeira categoria analisada diz respeito às dinâmicas digitais realizadas com as crianças no Jl, começando-se por identificar quais as tecnologias usadas pelas crianças no JI (Quadro 2).

\section{Quadro 2 - Excertos de conteúdo relativo às tecnologias usadas pelas crianças no JI}

\begin{tabular}{|c|c|c|}
\hline \multicolumn{3}{|c|}{ CATEGORIA: DINÂMICAS COM AS CRIANÇAS } \\
\hline \multirow{2}{*}{\multicolumn{3}{|c|}{\begin{tabular}{l}
\multicolumn{3}{l}{ Subcategoria: Tecnologias usadas pelas crianças no JI } \\
Nós
\end{tabular}}} \\
\hline & & \\
\hline Computador & 4 & $\begin{array}{l}\text { "Dentro da sala, nós temos várias áreas e uma das áreas é o } \\
\text { computador. Eles podem ir brincar a trabalhar" }(\mathrm{Ed} 3)\end{array}$ \\
\hline $\begin{array}{l}\text { Máquina } \\
\text { fotográfica }\end{array}$ & 4 & $\begin{array}{l}\text { "Embora a máquina (fotográfica) eu os deixe manusear algumas vezes, } \\
\text { principalmente aos mais velhos" (Ed1) }\end{array}$ \\
\hline Telemóvel & 2 & "O telemóvel eles também já usam para tirar fotografias" (Ed4) \\
\hline Impressora & 1 & "Depois vamos imprimir à impressora lá acima, da Secretaria" (Ed3) \\
\hline
\end{tabular}

Verificamos que todas as educadoras facultam dispositivos tecnológicos às crianças, sendo referidos o computador, a máquina fotográfica, o telemóvel e a impressora, o que mostra predisposição para a utilização de tecnologia no planeamento das atividades. Não foram mencionados outros dispositivos (scanner, tablet, webcam), embora tenham sido enumerados pela entrevistadora.

Relativamente às aplicações e conteúdos digitais, foram identificados seis tipos de programas utilizados pelas crianças no Jl: software didático, programas de desenho e pintura, programas de escrita, apresentações (PowerPoint e Prezi), jogos e histórias digitais (Quadro 3). Nesta questão, as educadoras referiam-se à utilização independente por parte das crianças, que, pelas respostas dadas, parece poder associar-se também a atividades de aprendizagem. 


\section{Quadro 3 - Excertos de conteúdo relativo às aplicações e conteúdos digitais no $\mathrm{JI}$}

\begin{tabular}{|c|c|c|}
\hline \multicolumn{3}{|c|}{ CATEGORIA: DINÂMICAS COM AS CRIANÇAS } \\
\hline \multicolumn{3}{|c|}{ Subcategoria: Aplicações e conteúdos digitais usados no Jl } \\
\hline Nós & F. & Unidade de registo (exemplo) \\
\hline $\begin{array}{l}\text { Programas de } \\
\text { escrita }\end{array}$ & 2 & $\begin{array}{l}\text { "Então vão brincar com as letras no Word para tentarem fazer ... compor o seu } \\
\text { texto, uma coisa muito simples" (Ed4) }\end{array}$ \\
\hline $\begin{array}{l}\text { Programas de } \\
\text { desenho e } \\
\text { pintura }\end{array}$ & 3 & "Têm ali alguns programas simples, de desenho, de pintura" (Ed3) \\
\hline $\begin{array}{l}\text { Software } \\
\text { didático }\end{array}$ & 3 & "CDs interativos, não só de jogos, mas de pesquisa de informação" (Ed4) \\
\hline $\begin{array}{l}\text { Programas de } \\
\text { apresentações }\end{array}$ & 2 & $\begin{array}{l}\text { "Eles também fazem apresentações de projetos em PowerPoint. Preparam, no } \\
\text { computador, uma coisa muito simples; copiar a imagem, por exemplo, num } \\
\text { projeto sobre os animais" (Ed3) }\end{array}$ \\
\hline Jogos & 2 & "Temos alguns jogos interativos" (Ed4) \\
\hline Histórias & 1 & $\begin{array}{l}\text { "São eles, muitas vezes, que escolhem, por iniciativa própria, ir para o } \\
\text { computador. Ou ver uma história, que temos lá histórias" (Ed3) }\end{array}$ \\
\hline
\end{tabular}

As atividades que as educadoras realizam com as crianças na sala de Jl, com recurso à tecnologia, são variadas e estão muito relacionadas com a utilização de recursos disponíveis na Internet, tendo algumas educadoras já iniciado as crianças em atividades sociais virtuais (videoconferência e Messenger). As respostas fazem crer que as educadoras do projeto têm facilidade e apetência para o planeamento de atividades com tecnologia (Quadro 4).

\section{Quadro 4 - Excertos de conteúdo relativo às atividades realizadas com tecnologia}

\begin{tabular}{|l|l|l|}
\hline \multicolumn{3}{|l|}{ CATEGORIA: DINÂMICAS COM AS CRIANÇAS } \\
\hline \multicolumn{2}{|l|}{ Subcategoria: Atividades que as educadoras realizam com tecnologia } \\
\hline Nós & F. & Unidade de registo (exemplo) \\
\hline Contar histórias & 2 & "Utilizo muito para conto de histórias" (Ed1) \\
\hline Músicas & 1 & $\begin{array}{l}\text { "Pesquisar, também, músicas de que eles falam e que muitas vezes eu não } \\
\text { conheço" (Ed1) }\end{array}$ \\
\hline $\begin{array}{l}\text { Pesquisas na } \\
\text { Internet }\end{array}$ & 3 & $\begin{array}{l}\text { "Pesquisas também, às vezes em torno de algum tema que estamos a } \\
\text { trabalhar, às vezes pode ser de uma necessidade que surge no momento, de } \\
\text { querer saber alguma coisa, ou também incutida por mim. Vamos procurar } \\
\text { saber mais, vamos pesquisar" (Ed1) }\end{array}$ \\
\hline $\begin{array}{l}\text { Videoconferência } \\
\text { "Temos miúdos que têm familiares no estrangeiro e quando eles vão para o } \\
\text { estrangeiro fazemos ligações Skype, o grupo com a criança que está fora" } \\
\text { (Ed2) }\end{array}$ \\
\hline $\begin{array}{l}\text { Messenger } \\
\text { Mostrar } \\
\text { vídeos/filmes }\end{array}$ & 1 & $\begin{array}{l}\text { "Outra coisa que os meus meninos gostam de fazer é mandar bonequinhos no } \\
\text { Facebook, pelo Messenger, aos pais. Então também fazemos isso" (Ed2) }\end{array}$ \\
\hline
\end{tabular}


De acordo com as educadoras, as crianças usam o computador todas as semanas, de forma independente. Esta frequência de acesso à tecnologia no Jl permite-Ihes familiarizarem-se com a sua utilização (Quadro 5).

\section{Quadro 5 - Excertos de conteúdo relativo à frequência de realização de dinâmicas digitais}

\begin{tabular}{|l|l|l|}
\hline \multicolumn{3}{|l|}{ CATEGORIA: DINÂMICAS COM AS CRIANÇAS } \\
\hline Subcategoria: Frequência de realização de dinâmicas digitais \\
\hline Nós & F. & Unidade de registo (exemplo) \\
\hline Diária & 2 & "Diariamente" (Ed2) \\
\hline Semanal & 1 & "A utilização do computador? Semanalmente, sim" (Ed1) \\
\hline Livre & 1 & $\begin{array}{l}\text { "Eles têm oportunidade de, livremente, quando querem, escolher a área do } \\
\text { computador para brincar e trabalhar" (Ed3) }\end{array}$ \\
\hline
\end{tabular}

Os maiores constrangimentos reportados pelas educadoras relacionam-se com meios técnicos (dispositivos desatualizados, falta de Internet na sala, falta de software interessante). Outros constrangimentos estão relacionados com questões de organização (falta de tempo, grupos grandes) e, ainda, falta de formação. Uma educadora identificou também a dificuldade do uso do rato como um problema recente das crianças, devido ao uso de dispositivos touch screen (Quadro 6). Contudo, mais do que ser um constrangimento, poderá constituir-se como uma oportunidade para as crianças manusearem este periférico.

A segunda categoria analisada refere-se às dinâmicas (atuais ou potenciais) de comunicação com os pais, usando a tecnologia (Quadros 7 a 10). Todas as educadoras usam o e-mail para comunicação com os pais. De notar que a Ed2 complementa o e-mail com outras estratégias de comunicação digital, combinando a rede social Facebook e o serviço Cloud, para fins diferentes. Segundo esta educadora, seria benéfica uma plataforma específica que agregasse todas as funcionalidades, num espaço seguro, onde os pais tivessem a confiança de partilhar informação privada dos filhos. A Ed1 refere ainda a criação e manutenção de um jornal digital, com divulgação das atividades realizadas com as crianças e partilha de links, entre outros conteúdos. Para esta educadora, a plataforma a desenvolver vem facilitar o seu trabalho, pois gostaria de ter um meio adequado e mais automatizado de partilhar este tipo de informação com os pais (Quadro 7). 


\section{Quadro 6 - Excertos de conteúdo relativo aos constrangimentos à realização de dinâmicas digitais com as crianças no Jl}

\begin{tabular}{|l|l|l|}
\hline \multicolumn{3}{|l|}{ CATEGORIA: DINÂMICAS COM AS CRIANÇAS } \\
\hline Subcategoria: Constrangimentos à realização de dinâmicas digitais \\
\hline Nós & F. & Unidade de registo (exemplo) \\
\hline Falta de tempo & 1 & $\begin{array}{l}\text { "Sinto falta, obviamente, de ter mais tempo com eles para explorar esses } \\
\text { conteúdos" (Ed1) }\end{array}$ \\
\hline $\begin{array}{l}\text { Falta de } \\
\text { dispositivos }\end{array}$ & 3 & $\begin{array}{l}\text { "Os computadores são um bocado antigos e fracos, que nós temos aqui, então } \\
\text { tenho uma dificuldade" (Ed3) }\end{array}$ \\
\hline $\begin{array}{l}\text { Grupo muito } \\
\text { grande }\end{array}$ & 1 & $\begin{array}{l}\text { "Eu sinto falta de ter disponibilidade para trabalhar as tais aplicações didáticas } \\
\text { que existem, e há delas, jogos, que até é mais fácil de eles interiorizarem os } \\
\text { conteúdos, mas só consigo fazer em atividades de grupo, não consigo fazer } \\
\text { de forma individualizada, porque o ambiente não propicia isso; depois, também } \\
\text { há barulho na sala, e eu não consigo, tenho 24 miúdos" (Ed2) }\end{array}$ \\
\hline $\begin{array}{l}\text { Dificuldade com } \\
\text { o rato }\end{array}$ & 1 & $\begin{array}{l}\text { "Alguns meninos, principalmente os mais novos, têm alguma dificuldade agora } \\
\text { no rato, por causa do touch screen" (Ed3) }\end{array}$ \\
\hline $\begin{array}{l}\text { Falta de } \\
\text { formação }\end{array}$ & 1 & $\begin{array}{l}\text { "Tenho alguma barreira, já não estou atualizada a nível do que é que há e de } \\
\text { como instalar as coisas no computador" (Ed3) }\end{array}$ \\
\hline $\begin{array}{l}\text { Falta de Internet } \\
\text { na sala }\end{array}$ & 2 & $\begin{array}{l}\text { "E mais acesso à Internet, também, esta sala não apanha tanto. Quando eu } \\
\text { quero usar com eles mais essas coisas, tenho que ser eu trazer a } \\
\text { informação, acaba por termos que nos deslocar lá acima, ou então trago o } \\
\text { meu portátil de casa" (Ed4) }\end{array}$ \\
\hline $\begin{array}{l}\text { Pouco software } \\
\text { educativo }\end{array}$ & 1 & $\begin{array}{l}\text { "Mais software educativo era interessante, mas como os meios que nós temos } \\
\text { são um bocado antigos..." (Ed3) }\end{array}$ \\
\hline
\end{tabular}

\section{Quadro 7 - Excertos de conteúdo relativo aos meios digitais usados para comunicação com os pais}

\begin{tabular}{|l|l|l|}
\hline CATEGORIA: DINÂMICAS COM OS PAIS \\
\hline Subcategoria: Meios digitais usados na comunicação com os pais \\
\hline Eós & F. & Unidade de registo (exemplo) \\
\hline Facebook & 4 & $\begin{array}{l}\text { "O e-mail uso, não diariamente, mas sobretudo nestes dias especiais ou } \\
\text { quando estamos a fazer um projeto e é preciso alguma coisa" (Ed4) }\end{array}$ \\
\hline Jornal digital & 1 & $\begin{array}{l}\text { "Sim, nós fazemos publicações no Facebook. Uma vez por mês, cada sala } \\
\text { publica um leque de fotografias e fazemos também partilha do que vai } \\
\text { acontecer - vamos sair, vamos aqui, festa de natal... Portanto, temos o } \\
\text { Facebook" (Ed2) }\end{array}$ \\
\hline Cloud & 1 & $\begin{array}{l}\text { "Nós temos um jornal semanal, às vezes quinzenal [risos], que envio, e } \\
\text { nesse jornal faço, digamos assim, uma síntese daquilo que fizemos nessa } \\
\text { semana ou nessa quinzena, mas normalmente é semanal. Faço um resumo, } \\
\text { coloco também hiperligações para canções que aprendemos, para histórias } \\
\text { que ouvimos, damos sugestões de coisas que estão a decorrer" (Ed1) }\end{array}$ \\
\hline & 1 & $\begin{array}{l}\text { "Temos uma pasta na Dropbox partilhada com o grupo da sala e uma vez } \\
\text { por mês publicamos as fotografias todas da sala. Todas, das atividades" } \\
\text { (Ed2) }\end{array}$ \\
\hline
\end{tabular}

Quando inquiridas sobre as funcionalidades e dinâmicas que a plataforma para o envolvimento parental poderia proporcionar, as respostas das educadoras foram variadas, ultrapassando as funcionalidades-padrão de redes sociais já existentes (Quadro 8). As educadoras foram propondo funcionalidades que Ihes facilitam a comunicação com os pais (comentários), agilizam o envio de informação aos pais (cadernetas digitais, ementas) e 
envolvem os pais na vida do Jl (divulgação das atividades realizadas, fotografias, vídeos e desenhos das crianças, sugestão de atividades para realizar em casa, feedback dos pais). De notar a sugestão de três áreas, pela sua especificidade: 1) o historial da criança e do grupo, ou seja, uma área onde se vá guardando a informação da criança e do grupo para consulta futura, com permissões de acesso individuais e de grupo; 2) uma área privada com informação de saúde, como medicação e doses a ministrar nas doenças, alergias, etc.; 3) a publicação de livros dinâmicos com histórias criadas com trabalhos das crianças, para partilhar com os pais.

\section{Quadro 8 - Excertos de conteúdo relativo às dinâmicas possíveis de realizar com uma plataforma para envolvimento parental}

\begin{tabular}{|c|c|c|}
\hline \multicolumn{3}{|c|}{ CATEGORIA: DINÂMICAS COM OS PAIS } \\
\hline \multicolumn{3}{|c|}{ Subcategoria: Dinâmicas possíveis com a futura plataforma } \\
\hline Nós & $\mathbf{F}$. & Unidade de registo (exemplo) \\
\hline $\begin{array}{l}\text { Historial da } \\
\text { criança/grupo }\end{array}$ & 3 & $\begin{array}{l}\text { "A plataforma poderia permitir um registo biográfico, que nós também temos } \\
\text { em papel, mas ao longo do tempo... o histórico todo da criança, quer em } \\
\text { termos de saúde, quer em termos de evolução, os registos, as avaliações } \\
\text { que nós fazemos" (Ed2) }\end{array}$ \\
\hline $\begin{array}{l}\text { Envio de } \\
\text { comentários }\end{array}$ & 2 & $\begin{array}{l}\text { "Hoje em dia, como andamos todos com o telemóvel, com a Internet todo o } \\
\text { dia ligada, era engraçado ser uma coisa mais interativa, que nós } \\
\text { postássemos as atividades que fazemos e eles [pais] pudessem comentar" } \\
\text { (Ed4) }\end{array}$ \\
\hline $\begin{array}{l}\text { Divulgação de } \\
\text { atividades } \\
\text { realizadas na } \\
\text { sala }\end{array}$ & 2 & $\begin{array}{l}\text { "Há uma peça de teatro, mesmo aqui da sala, uma coisa muito simples, } \\
\text { poder-se-ia colocar, quando estão a aprender uma canção nova colocar a } \\
\text { canção, a história..." (Ed1) }\end{array}$ \\
\hline $\begin{array}{l}\text { Sugestões de } \\
\text { atividades } \\
\text { (leituras, } \\
\text { passeios, etc.) }\end{array}$ & 2 & $\begin{array}{l}\text { "Troca entre escola e família, desde livros interessantes para ler, locais a } \\
\text { visitar, sugestões de atividades que surgem, ou no teatro, ou espetáculos..." } \\
\text { (Ed3) }\end{array}$ \\
\hline $\begin{array}{l}\text { Feedback dos } \\
\text { pais }\end{array}$ & 2 & $\begin{array}{l}\text { "Há tanta coisa que se perde... sugestões, críticas, mesmo, o que fosse... } \\
\text { acho que era muito bom, gratificante" (Ed4) }\end{array}$ \\
\hline Vídeos & 1 & $\begin{array}{l}\text { "Penso que é um bocadinho de tudo: envio de comentários, desenhos, vídeos, } \\
\text { recados... acho que há imensas coisas" (Ed1) }\end{array}$ \\
\hline Recados & 1 & $\begin{array}{l}\text { "Se calhar uma área de recados, para relembrar recados, porque no dia a } \\
\text { dia muitos ficam esquecidos" (Ed1) }\end{array}$ \\
\hline Ementas & 1 & $\begin{array}{l}\text { "Para as ementas, para a vivência toda do jardim de infância, acho que } \\
\text { poderia ser importante" (Ed1) }\end{array}$ \\
\hline $\begin{array}{l}\text { Informação de } \\
\text { saúde }\end{array}$ & 1 & $\begin{array}{l}\text { "plataforma que permitisse agrupar todo o historial da criança, por exemplo, vai } \\
\text { ao médico..." (Ed2) }\end{array}$ \\
\hline Desenhos & 1 & $\begin{array}{l}\text { "Penso que é um bocadinho de tudo: envio de comentários, desenhos, vídeos, } \\
\text { recados... acho que há imensas coisas" (Ed1) }\end{array}$ \\
\hline Fotografias & 1 & "nós postávamos imagens do projeto que estamos a fazer" (Ed4) \\
\hline $\begin{array}{l}\text { Publicação de } \\
\text { PDFs dinâmicos } \\
\text { das crianças }\end{array}$ & 1 & $\begin{array}{l}\text { "Livros que nós vemos online que parece que conseguimos folhear... Acho } \\
\text { que era tão giro que conseguíssemos postar os projetos que eles fazem e, à } \\
\text { noite, eles, com os pais, iam a essa ferramenta e apresentavam, como se } \\
\text { estivessem a ler, um projeto, ou uma história, ou o que fosse, também mais } \\
\text { dirigido a eles" (Ed4) }\end{array}$ \\
\hline
\end{tabular}


Relativamente à frequência de utilização e atualização de informação na plataforma, todas as educadoras mencionaram a utilização semanal; no entanto, uma mencionou que há informação que pode ser atualizada diariamente e outra trimestralmente (Quadro 9).

\section{Quadro 9 - Excertos de conteúdo relativo à frequência de uso de uma plataforma para o envolvimento parental}

\begin{tabular}{|l|l|l|}
\hline \multicolumn{2}{|l|}{ CATEGORIA: USO DA PLATAFORMA } \\
\hline Subcategoria: Frequência de uso de plataforma \\
\hline Nós & F. & Unidade de registo (exemplo) \\
\hline Semanal & 4 & $\begin{array}{l}\text { "Fazermos como costumamos fazer aqui na escola, de irmos falando sobre o } \\
\text { dia a dia na sala e as coisas que fazemos com os meninos... Se assim for, } \\
\text { nós fazemos isso semanalmente" (Ed4) }\end{array}$ \\
\hline Diária & 1 & $\begin{array}{l}\text { "Eu entendo que existem determinadas informações que têm que ser diárias; } \\
\text { por exemplo, se a criança andou adoentada, é preciso fazer o registo no dia, } \\
\text { como é que a criança passou o dia, fez febre às X horas... Isso é diário" } \\
\text { (Ed2) }\end{array}$ \\
\hline Trimestral & 1 & $\begin{array}{l}\text { "As avaliações são trimestrais, os perfis são atualizados trimestralmente; } \\
\text { depende do tipo de informação" (Ed2) }\end{array}$ \\
\hline
\end{tabular}

Os dispositivos indicados para utilização da plataforma são o computador e o telemóvel (Quadro 10). Nenhuma educadora mencionou o tablet como dispositivo para aceder à plataforma. O computador é visto como uma ferramenta para trabalhar e inserir muita informação. O telemóvel é preferido para consultar informação e responder rapidamente. Esta resposta indica a necessidade de preparar uma plataforma que se adapte a ambos os dispositivos.

\section{Quadro 10 - Excertos de conteúdo relativo às dinâmicas possíveis de realizar com uma plataforma para envolvimento parental}

\begin{tabular}{|l|l|l|}
\hline \multicolumn{2}{|l|}{ CATEGORIA: USO DA PLATAFORMA } \\
\hline Subcategoria: Dispositivos para uso da plataforma \\
\hline Nós & F. & Unidade de registo (exemplo) \\
\hline Computador & 3 & "Por exemplo, no meu caso, eu acho que o computador" (Ed3) \\
\hline Telemóvel & 3 & $\begin{array}{l}\text { "Os pais dizem-me... fazem sempre referência ao telemóvel, porque andam } \\
\text { com a Internet, sempre ali, com as notificações, sempre a receber, sempre a } \\
\text { receber... É uma coisa que está ali no momento, e não se vão esquecer, } \\
\text { porque fica lá marcado" (Ed4) }\end{array}$ \\
\hline
\end{tabular}

As educadoras referiram várias vantagens (Quadro 11) e alguns constrangimentos (Quadro 12), relativamente ao uso de uma plataforma para 
o envolvimento parental. As vantagens identificadas pelas educadoras, no que se refere à criação de uma plataforma específica para o envolvimento parental, são: promover a participação ativa dos pais; ser um meio mais dinâmico e interativo de comunicação; centrar informação e serviços; disponibilizar a informação em qualquer hora e local; facilitar a conversa entre pais e filhos sobre a escola; separar o espaço de comunicação pessoal e profissional; permitir a partilha do dia a dia das crianças; favorecer uma comunicação escola-família enriquecedora e possibilitar o envolvimento das crianças. As vantagens foram identificadas, pelas educadoras, de acordo com as funcionalidades e dinâmicas que tinham descrito anteriormente. Embora algumas vantagens sejam genéricas e possam ser satisfeitas com a utilização de ferramentas Web já existentes, algumas estão relacionadas com funcionalidades desenvolvidas especificamente para o objetivo (Quadro 11).

\section{Quadro 11 - Excertos de conteúdo relativo às vantagens da utilização de uma plataforma para o envolvimento parental}

\begin{tabular}{|c|c|c|}
\hline \multicolumn{3}{|c|}{ CATEGORIA: VANTAGENS E CONSTRANGIMENTOS } \\
\hline Nós & F. & Unidade de registo (exemplo) \\
\hline $\begin{array}{l}\text { Participação } \\
\text { ativa dos pais }\end{array}$ & 2 & $\begin{array}{l}\text { "Acho que eles, podendo aceder no computador ou no telemóvel, diariamente, } \\
\text { que... de certeza que aí poderá haver mais feedback" (Ed3) }\end{array}$ \\
\hline $\begin{array}{l}\text { Meio dinâmico e } \\
\text { interativo }\end{array}$ & 2 & $\begin{array}{l}\text { "é um bocadinho o que faço no jornal com os links, mas que realmente ali } \\
\text { teria outro sentido e poderia ser muito mais dinâmico e interativo também. O } \\
\text { jornal não é assim tão interativo" (Ed1) }\end{array}$ \\
\hline $\begin{array}{l}\text { Fomentar } \\
\text { conversas sobre } \\
\text { o Jl }\end{array}$ & 2 & $\begin{array}{l}\text { "Irem acompanhando, de facto, o desenvolvimento deles, e poderem, em } \\
\text { casa, ter tema de conversa, porque basta apenas só saber a temática que } \\
\text { se anda a trabalhar para encetar uma conversa e, a partir daí, as coisas já } \\
\text { começarem a fluir e a conversação entre os pais e as crianças ser bastante } \\
\text { melhor" (Ed1) }\end{array}$ \\
\hline $\begin{array}{l}\text { Centrar } \\
\text { informação e } \\
\text { serviços }\end{array}$ & 2 & $\begin{array}{l}\text { "às vezes uma pessoa não tem tempo de escrever ou procurar o e-mail, tenho } \\
\text { que procurar o e-mail da [nome] para mandar... E assim é logo, é instantâneo; } \\
\text { se eles recebem, pelo menos, veem, e há possibilidade de sentirmos o } \\
\text { feedback deles" (Ed3) }\end{array}$ \\
\hline $\begin{array}{l}\text { Separar espaço } \\
\text { pessoal e } \\
\text { profissional }\end{array}$ & 2 & $\begin{array}{l}\text { "Quando os pais me convidam no Facebook, eu aceito, mas o que é certo é } \\
\text { que aquela minha página pessoal passou a ser um bocado misturar o } \\
\text { profissional com o pessoal" (Ed2) }\end{array}$ \\
\hline $\begin{array}{l}\text { Disponivel em } \\
\text { qualquer hora e } \\
\text { lugar }\end{array}$ & 2 & $\begin{array}{l}\text { "a informação fica registada e de fácil acesso a todos. A qualquer hora do } \\
\text { dia, consoante cada um, a informação está lá e cada um vai consultá-la } \\
\text { quando quiser e consoante a sua disponibilidade. Em termos de organização } \\
\text { de tempo, acho que é uma vantagem" (Ed2) }\end{array}$ \\
\hline $\begin{array}{l}\text { Partilha do dia a } \\
\text { dia das crianças }\end{array}$ & 1 & $\begin{array}{l}\text { "Os pontos fortes, de facto, é a partilha daquilo que é o dia a dia dos filhos. } \\
\text { Sabemos que os meninos estão aqui } 10 \text { horas por dia e para os pais é } \\
\text { extremamente importante perceber aquilo que foi o dia deles. Porque ao fim } \\
\text { do dia perguntamos "O que é que fizeste hoje?» e a resposta é "Não fiz } \\
\text { nada". Muitas das vezes, não é? Principalmente numa fase inicial, dos } 3,4 \\
\text { anos, isso é o ponto forte" (Ed1) }\end{array}$ \\
\hline $\begin{array}{l}\text { Comunicação } \\
\text { escola-família } \\
\text { enriquecedora }\end{array}$ & 1 & $\begin{array}{l}\text { "Mas acho que ia haver umas trocas de comunicação, que acho que ia ser } \\
\text { muito enriquecedor. A grande vantagem eu acho que é mesmo essa: } \\
\text { manter, estreitar cada vez mais os laços entre casa e escola" (Ed4) }\end{array}$ \\
\hline $\begin{array}{l}\text { Envolvimento } \\
\text { das crianças }\end{array}$ & 1 & $\begin{array}{l}\text { "até mesmo não serem só os pais a darem feedback, os meninos podiam } \\
\text { também escrever, os pais ajudavam: "Ah, eu fiz esse projeto e também } \\
\text { aprendi isto e aquilo", e íamos partilhando, aquilo acabava por envolver } \\
\text { também as crianças, o grupo" (Ed4) }\end{array}$ \\
\hline
\end{tabular}


Também são referidos alguns constrangimentos ao uso da plataforma, como a falta de tempo das educadoras, a não adesão ou a dificuldade de acesso dos pais, a necessidade de contacto presencial, o mau uso ou uso abusivo da plataforma e as questões de privacidade. Este último ponto terá que ser acautelado, definindo níveis de privacidade no acesso à informação que se publica na plataforma, nomeadamente quais os conteúdos a que acede cada membro, individualmente e em grupo. Exclui-se a possibilidade de acesso ou partilha a pessoas fora do grupo, pois ultrapassa o âmbito do projeto e poderia tornar-se um constrangimento à utilização da plataforma, por parte dos pais.

\section{Quadro 12 - Excertos de conteúdo relativo aos constrangimentos à utilização de uma plataforma para o envolvimento parental}

\begin{tabular}{|l|l|l|}
\hline \multicolumn{2}{|l|}{ CATEGORIA: VANTAGENS E CONSTRANGIMENTOS } \\
\hline Subcategoria: Constrangimento à utilização da plataforma \\
\hline Nós & F. & Unidade de registo (exemplo) \\
\hline Falta de tempo & 2 & $\begin{array}{l}\text { "Falta de tempo. Eu, principalmente, neste caso. Porque, pronto, acho que é } \\
\text { um constrangimento de quase toda a gente, mas eu, como faço também a } \\
\text { coordenação pedagógica, é-me difícil arranjar tempo para tudo" (Ed3) }\end{array}$ \\
\hline $\begin{array}{l}\text { Não adesão dos } \\
\text { pais }\end{array}$ & 2 & $\begin{array}{l}\text { "A resposta não positiva dos pais, de não aderirem à ferramenta, mas acho } \\
\text { que a maioria iria aderir" (Ed1) }\end{array}$ \\
\hline $\begin{array}{l}\text { Mau uso/uso } \\
\text { abusivo }\end{array}$ & 1 & $\begin{array}{l}\text { "Se as pessoas começarem a usar isso para falar de coisas que, se calhar, } \\
\text { não têm interesse para a comunidade que estamos a falar, em geral. } \\
\text { Aproveitar esses momentos para fazerem questões que podiam chegar de } \\
\text { manhã e fazer. Perder o rumo e aproveitarem para isso, como às vezes } \\
\text { acontece" (Ed4) }\end{array}$ \\
\hline $\begin{array}{l}\text { Dificuldade de } \\
\text { acesso }\end{array}$ & 1 & $\begin{array}{l}\text { "Depois, nem todos poderiam, eventualmente, ter acesso; apesar de a } \\
\text { Internet e o uso da Internet estar generalizado, ainda há um ou outro caso, } \\
\text { portanto nunca pode ser substituto. Tem que continuar a haver [papel], } \\
\text { porque há pessoas ou que têm acesso mas não têm informação, ou que não } \\
\text { sabem utilizar ou que não estão para isso" (Ed2) }\end{array}$ \\
\hline $\begin{array}{l}\text { Receio quanto à } \\
\text { privacidade }\end{array}$ & 1 & $\begin{array}{l}\text { "e depois esta questão da privacidade também, de que eles são cada vez } \\
\text { mais ciosos e que teria de estar muito bem acautelada" (Ed2) }\end{array}$ \\
\hline $\begin{array}{l}\text { Necessidade de } \\
\text { contacto } \\
\text { presencial }\end{array}$ & 1 & $\begin{array}{l}\text { "Aqui eu acho que ainda há uma necessidade grande e acho que é } \\
\text { importante um contacto direto e que os pais têm mais necessidade" (Ed1) }\end{array}$ \\
\hline
\end{tabular}

\section{Conclusões}

A escolha da entrevista semiestruturada, como técnica de recolha de dados, revelou-se adequada, pois permitiu reunir informação organizada sobre as dinâmicas digitais que as educadoras desenvolvem com as crianças e com os pais, bem como recolher as opiniões e sugestões para o desenvolvimento da plataforma digital para o envolvimento parental, obtendo assim uma visão mais completa e pormenorizada do lado profissional. 
Foi possível verificar que as educadoras integradas no projeto têm conhecimento e experiência no uso das tecnologias, tanto para realizar atividades em sala de $\mathrm{Jl}$ com as crianças, como para comunicar com os pais. Têm uma postura positiva face às tecnologias, promovem frequentemente atividades digitais com as crianças e consideram importante a aproximação à tecnologia, nesta faixa etária. Estas atitudes e práticas são concordantes com a maioria das educadoras questionadas por Brito (2010), mostrando abertura e valorização do uso das tecnologias para aprendizagem no jardim de infância.

Relativamente à plataforma tecnológica, foram apresentadas inúmeras sugestões de funcionalidades e dinâmicas, e identificadas vantagens e constrangimentos, mas domina a opinião de utilidade e benefício na aproximação, comunicação, relação e envolvimento mais ativo dos pais. Esta perspetiva é documentada por vários autores, que associam a comunicação escola-família ao envolvimento parental na aprendizagem (Fantuzzo et al., 2013; Stevenson \& Baker, 1987), às boas relações entre pais e educadores (Diamond et al., 2013) e aos bons resultados dos alunos (Hilado et al., 2013; Lunts, 2003; Melhuish et al., 2008).

Por outro lado, há poucas alusões à inclusão da criança na utilização da plataforma e não há menções ao impacto ou benefício que uma plataforma para o envolvimento parental pode trazer à aprendizagem das crianças, o que parece revelar que as educadoras perspetivam uma ferramenta mais centrada na comunicação e partilha de informação entre adultos.

De acordo com os dados recolhidos nas entrevistas às educadoras, conclui-se que a plataforma deve permitir centrar, num só espaço, a informação oficial do Jl, contactos diretos dos pais e serviços específicos, como o historial da criança e do grupo, atividades realizadas no Jl e ideias de atividades para desenvolver com as crianças. Neste sentido, é útil para as educadoras, pela rapidez e automatização de tarefas de comunicação e partilha de informação.

Em termos de funcionalidades sociais, as educadoras referem que os pais têm problemas com as questões de privacidade das redes sociais. Por este motivo, planeia-se um ambiente fechado ao grupo, sem possibilidade de partilha externa, que gere mais confiança e predisposição à participação, comunicação e feedback. Deverão existir áreas de grupo (em que todos os 
membros veem a informação) e áreas privadas (para comunicação bilateral entre educador e encarregado de educação), conforme o tipo de informação a partilhar.

Também foi mencionada pelas educadoras a importância de separar o espaço profissional do espaço pessoal que têm nas redes sociais. Uma plataforma que reúna conteúdos e diferentes formas de comunicação com os pais vai permitir distanciar estes dois espaços, pois os pais não terão necessidade de aceder ao espaço pessoal da rede social para comunicar com a educadora.

As educadoras utilizam o computador e o telemóvel para fins diferentes e associam a execução de algumas tarefas ao computador e a execução de outras ao telemóvel, pelo que a plataforma deverá adaptar-se a diferentes dispositivos, para ter uma utilização mais eficaz.

As educadoras apontam a falta de acesso a recursos educativos digitais atualizados, mas também afirmam que usam a tecnologia para fazer pesquisas, contar histórias, mostrar vídeos e músicas. Por conseguinte, a plataforma deverá ter uma área de links para recursos educativos úteis, que possam ser partilhados pelos membros, para realização de atividades de aprendizagem, em casa e no Jl. Os recursos devem ser selecionados criticamente, tendo em conta o seu contributo para o desenvolvimento da linguagem, pensamento matemático e conhecimento do mundo (Amante, 2007). Devem estar adaptados aos interesses da criança (Clements \& Sarama, 2002), envolvê-la na construção do conhecimento (Papert, 1996) e potenciar a criatividade e a expressividade (Crook, 2008).

Este estudo permitiu identificar as necessidades das educadoras e conhecer as suas expetativas relativamente a uma plataforma para o envolvimento parental. Esta informação será usada na definição de especificações funcionais que vão orientar o desenvolvimento da plataforma.

\section{Notas}

1 Investigação com o apoio da FCT e do FSE, no âmbito do III QCA. Ref.: SFRH/BDE/95701/2013. 


\section{Referências}

Amante, L. (2007). As TIC na escola e no jardim de infância: Motivos e fatores para a sua integração. Sísifo: Revista de Ciências da Educação, 3, 51-64.

Bardin, L. (1977). Análise de conteúdo. Lisboa: Edições 70.

Bogdan, R., \& Biklen, S. (1994). Investigação qualitativa em educação - Uma introdução à teoria e aos métodos. Porto: Porto Editora.

Braga, I., Ramos, A., \& Braga, J. (2015). Tecnologias digitais no pré-escolar: O YouTube para aprender e partilhar. In M. J. Gomes, A. J. Osório, \& L. Valente (Orgs.), Actas da IX Conferência Internacional de TIC na Educação Challenges 2015: Meio Século de TIC na Educação, Half a Century of ICT in Education (pp. 280294). Universidade do Minho: Centro de Competência TIC do Instituto de Educação. http://repositorium.sdum.uminho.pt/ handle/1822/35238

Brito, R. (2010). As TIC em educação pré-escolar portuguesa: Atitudes, meios e práticas de educadores e crianças. In A. Osório, \& M. Pinto (Orgs.), Atas do I Encontro @rcaComum (pp. 3-11). Universidade do Minho. Instituto de Educação. http://hdl.handle.net/10400.26/2509

Clements, D. H., \& Sarama, J. (2002). Teaching with computers in early childhood education: Strategies and professional development. Journal of Early Childhood Teacher Education, 23(3), 215-226. http://dx.doi.org/10.1080/1090102020230 305

Cohen, L., Manion, L., \& Morrison, K. (2007). Research methods in education (6th ed.). London: Routledge.

Costa, F. A., Rodriguez, C., \& Fradão, S. (2012). Repensar as TIC na educação: O professor como agente transformador ( $1^{\mathrm{a}}$ ed.). Carnaxide: Santillana.

Coutinho, C. (2013). Metodologia de investigação em ciências sociais e humanas: Teoria e prática ( $2^{\mathrm{a}}$ ed.). Lisboa: Almedina.

Crook, C. (2008). Web 2.0 technologies for learning: The current landscape Opportunities, challenges and tensions. Becta I Web 2.0 technologies for learning at Key Stages 3 and 4. http://dera.ioe.ac.uk/1474

Desforges, C., \& Abouchaar, A. (2003). The impact of parental involvement, parental support and family education on pupil achievements and adjustment: A literature review (Vol. 433). Nottingham: DfES Publications.

Diamond, K. E., Justice, L. M., Siegler, R. S., \& Snyder, P. A. (2013). Synthesis of IES research on early intervention and early childhood education (NCSER 20133001). Washington, DC: National Center for Special Education Research. http://eric.ed.gov/?id=ED544212

Fan, X., \& Chen, M. (2001). Parental involvement and students' academic achievement: A meta-analysis. Educational Psychology Review, 13(1), 1-22. https://doi.org/ 10.1023/A:1009048817385

Fantuzzo, J., Gadsden, V., Li, F., Sproul, F., McDermott, P., Hightower, D., \& Minney, A. (2013). Multiple dimensions of family engagement in early childhood education: Evidence for a short form of the Family Involvement Questionnaire. Early Childhood Research Quarterly, 28(4), 734-742. https://doi.org/10.1016/ j.ecresq.2013.07.001 
Faria, A., \& Ramos, A. (2011). Redes sociais no jardim de infância para aprender e partilhar com a família e a comunidade. In A. Lozano, M. Uzquiano, A. Rioboo, J. Blanco, B. Silva, \& L. Almeida (Orgs.), Libro de Actas do XI Internacional Galego-Portugués de Psicopedagoxía (pp. 3-13). Corunha: Faculdade de Ciências da Educação. http://repositorium.sdum.uminho.pt/handle/1822/33664

Fraenkel, J. R., \& Wallen, N. E. (2009). The nature of qualitative research. How to design and evaluate research in education (7th ed.). Boston: McGraw-Hill.

Hilado, A. V., Kallemeyn, L., \& Phillips, L. (2013). Examining understandings of parent involvement in early childhood programs. Early Childhood Research \& Practice, 15(2), 1-14. http://eric.ed.gov/?id=EJ1020689

Hong, S. B., \& Trepanier-Street, M. (2004). Technology: A tool for knowledge construction in a Reggio Emilia inspired teacher education program. Early Childhood Education Journal, 32(2), 87-94. https://doi.org/10.1007/s10643-0047971-z

Kalas, I. (2012). ICTs in early childhood care and education - Policy Brief. Moscow: UNESCO Institute for Information Technologies in Education. http://www.iite.unesco.org/publications/3214720

Laranjeiro, D., Antunes, M. J., \& Santos, P. (2016). Plataforma tecnológica para o envolvimento parental na aprendizagem das crianças que frequentam o jardimde-infância - Estudo exploratório sobre as necessidades dos pais. In N. Pedro, A. Pedro, J. F. Matos, J. Piedade, \& M. Fonte (Orgs.), Digital Technologies \& Future School: Atas do IV Congresso Internacional TIC e Educação 2016 [(artigos selecionados] (pp. 366-386). Lisboa: Instituto de Educação da Universidade de Lisboa. https://cld.pt/dl/download/e7500488-3c2a-4d99- 9de0ade4c5cc9aba/Livro_Artigos.pdf

Lunts, E. (2003). Parental involvement in children's education: Connecting family and school by using telecommunication technologies. Meridian: A Middle School Computer Technologies Journal, 6(1). https://www.ncsu.edu/meridian/ win2003/involvement/involvement.pdf

Melhuish, E. C., Phan, M. B., Sylva, K., Sammons, P., Siraj-Blatchford, I., \& Taggart, B. (2008). Effects of the home learning environment and preschool center experience upon literacy and numeracy development in early primary school. Journal of Social Issues, 64(1), 95-114. http://dx.doi.org/doi:10.1111/ j.15404560.2008.00550.x

National Association for the Education of Young Children. (2012). Technology and interactive media as tools in early childhood programs serving children from birth through age 8. Washington DC: National Association for the Education of Young Children. http://www.naeyc.org/files/naeyc/ PS_technology_WEB.pdf

Papert, S. (1996). The connected family: Bridging the digital generation gap. Atlanta, GA: Longstreet Press.

Pereira, A. (2014). "Eu ajudo-te, é fácil, eu também não sei escrever": Impacto das tecnologias educativas, em contexto de jardim de infância, num processo de desenvolvimento de literacia digital e intergeracional (Dissertação de mestrado). Universidade do Minho, Braga. http://repositorium.sdum.uminho.pt/handle/ $1822 / 35874$ 
Prensky, M. (2001). Digital natives, digital immigrants. On the Horizon MCB University Press, 9(5), 1-6. http://www.emeraldinsight.com/doi/ pdfplus/10.1108/1074812 0110424816

Reynolds, A. J., \& Shlafer, R. (2010). Parent involvement in early education. In S. L. Christenson \& A. L. Reschly (Eds.), Handbook of school-family partnerships (pp. 158-174). London: Routledge.

Santos, Z. (2013). E-TIC-Tando a escola: Possibilidades do uso da web na educação infantil. Nuevas Ideas en Informatica Educativa, 9, 479-482. http://www.tise.cl/ volumen9/TISE2013/479-482.pdf

Sonnenschein, S., Stapleton, L. M., \& Metzger, S. R. (2014). What parents know about how well their children are doing in school. The Journal of Educational Research, 107(2), 152-162. http://dx.doi.org/doi:10.1080/00220671.2013.788987

Stevenson, D. L., \& Baker, D. P. (1987). The family-school relation and the child's school performance. Child Development, 58(5), 1348-1357.

Teixeira, S. (2014). Recursos digitais no jardim de infância: A narrativa digital para promover multiliteracias (Dissertação de mestrado). Universidade do Minho, Braga. http://hdl.handle.net/1822/36023

United Nations Educational, Scientific and Cultural Organization. (2011). Transforming education: The power of ICT policies. France: Education Sector UNESCO. 
DIGITAL TECHNOLOGIES FOR LEARNING ACTIVITIES WITH CHILDREN AND PARENTAL INVOLVEMENT IN KINDERGARTEN: AN EXPLORATORY STUDY ON THE NEEDS OF KINDERGARTEN TEACHERS

\begin{abstract}
Digital technologies are being increasingly used by parents and kindergarten teachers to perform learning activities with children, such as access the Internet, make an online search or play an educational game. The development of a technological platform that promotes communication and content sharing between parents and kindergarten teachers can enhance parental involvement in children's learning and bring new dynamics to kindergarten classrooms. Based on interviews with four kindergarten teachers, this study aims to find out how they use technology in kindergartens to perform learning activities with children and share information with parents, in order to facilitate their involvement and participation. It also aims to understand how these activities could be expanded through the development of a digital platform with specific features. The results indicate that the platform should gather official information from the kindergarten and activities carried out with children, direct contacts of the parents, suggestions and links to educational resources.
\end{abstract}

Keywords

Kindergarten; ICT; Parental involvement; Learning

LES TECHNOLOGIES DIGITALE DANS L'APPRENTISSAGE DES ENFANTS ET LA PARTICIPATION DES PARENTS A LE JARDIN D'ENFANTS. ÉTUDE DIAGNOSTIQUE SUR LES BESOINS DES ÉDUCATEURS DE L'ENFANCE

Résumé

L'utilisation des technologies par les parents et les éducateurs du jardin d'enfants pour effectuer des activités qui favorisent l'apprentissage des 
enfants, par exemple, faire de la recherche à l'Internet ou jouer un jeu éducatif, est de plus en plus commune. La conception d'une plateforme technologique qui favorise la communication entre les parents et les éducateurs peut accroître la participation des parents dans l'apprentissage des enfants et apporter une nouvelle dynamique dans le groupe d'enfants. Cette étude, basée sur des entretiens avec quatre éducateurs, vise à découvrir comment elles utilisent la technologie pour faire des activités d'apprentissage avec les enfants et communiquer avec les parents, afin de faciliter leur participation. Elle cherche également à comprendre comment ces activités pourraient être développées avec une plateforme digitale. Les résultats indiquent que la plateforme devrait recueillir des informations officielles du jardin d'enfants et des activités menées avec les enfants, les contacts directs des parents, les suggestions et les liens ver des ressources éducatives.

Mots-clé

Jardin d'enfants; TIC; Participation des parents; Apprentissage

Recebido em março 2017 Aceite para publicação em maio 2017

i Departamento de Educação e Psicologia e Centro de Investigação em Didática e Tecnologia na Formação de Formadores (CIDTFF), Universidade de Aveiro, Portugal.

ii Departamento de Comunicação e Arte - DigiMedia, Universidade de Aveiro, Portugal.

iii Departamento de Educação e Psicologia e Centro de Investigação em Didática e Tecnologia na Formação de Formadores (CIDTFF), Universidade de Aveiro, Portugal.

Toda a correspondência relativa a este artigo deve ser enviada para: Maria João Antunes, Universidade de Aveiro, Campus Universitário de Santiago, Departamento de Comunicação e Arte, 3810-193 Aveiro. E-mail: mariajoao@ua.pt 